\title{
Phosphoprotein enriched in astrocytes-15 is expressed in mouse testis and protects spermatocytes from apoptosis
}

\author{
S C Mizrak , F Renault-Mihara², M Párraga ${ }^{3}$, J Bogerd ${ }^{1}$, H J G van de Kant ${ }^{1}$, P P López-Casas ${ }^{3}$, \\ $M \mathrm{Paz}^{3}$, J del Mazo ${ }^{3}$ and D G de Rooij ${ }^{1,4}$ \\ ${ }^{1}$ Department of Endocrinology, Faculty of Biology, Utrecht University, Padualaan 8, $3584 \mathrm{CH}$, Utrecht, The \\ Netherlands, ${ }^{2}$ INSERM U752-Chaire de Neuropharmacologie, Collège de France, Paris Cedex05, France, \\ ${ }^{3}$ Department of Cell and Developmental Biology, Centro de Investigaciones Biológicas, CSIC, Ramiro de Maeztu 9, \\ Madrid, Spain and ${ }^{4}$ Department of Cell Biology, UMCU, Utrecht University, 3584 CX, Utrecht, The Netherlands \\ Correspondence should be addressed to S C Mizrak; Email: s.c.mizrak@bio.uu.nl
}

M Párraga is now at Department Biomedical Sciences, Centro de Investigaciones Médicas, Escuela de Medicina, Universidad de Valparaíso, Hontaneda 2664, Valparaíso Chile

\begin{abstract}
Phosphoprotein enriched in astrocytes (PEA-15) is a $15 \mathrm{kDa}$ acidic serine-phosphorylated protein expressed in different cell types, especially in the CN. We initially detected the expression of PEA-15 in primary cultures of Sertoli cells. To assess the presence and localization of PEA-15 in the mouse testis, we studied the expression pattern of the PEA-15 protein by immunohistochemistry and mRNA by in situ hybridization. Both the protein and the mRNA of PEA-15 were localized in the cytoplasm of Sertoli cells, all types of spermatogonia, and spermatocytes up till zygotene phase of the meiotic prophase. Subsequently, with ongoing development of the spermatocytes, the expression decreased and was very low in the cytoplasm of diplotene spermatocytes. To analyze the possible role of PEA-15 in the developing testis, null mutants for PEA-15 were examined. As the PEA-15 C terminus contains residues for ERK binding, we studied possible differences between the localization of the ERK2 protein in wild type (WT) and PEA-15 ${ }^{-1-}$ mice. In the WT testis, ERK2 was localized in the cytoplasm of Sertoli cells, B spermatogonia, preleptotene, leptotene, and zygotene spermatocytes, whereas in the KO testis, ERK2 was primarily localized in the nuclei of these cells and only little staining remained in the cytoplasm. Moreover, in PEA-15-deficient mice, significantly increased numbers of apoptotic spermatocytes were found, indicating an anti-apoptotic role of PEA-15 during the meiotic prophase. The increased numbers of apoptotic spermatocytes were not found at a specific step in the meiotic prophase.

Reproduction (2007) 133 743-751
\end{abstract}

\section{Introduction}

PEA-15 (phosphoprotein enriched in astrocytes, $15 \mathrm{kDa}$ ) has been originally identified in the $\mathrm{CN}$ (Araujo et al. 1993, Danziger et al. 1995, Estelles et al. 1996) as a multifunctional protein implicated in various physiological and pathological processes (Renault et al. 2003), playing an anti-apoptotic role in cellular pathways in several cell types (Condorelli et al. 1998, Kitsberg et al. 1999), including cancer cells (Hao et al. 2001). It contains a death effector domain (DED) at its $\mathrm{N}$ terminus, thus sharing homology with other proteins involved in apoptosis (Kitsberg et al. 1999). One of the apoptotic pathways, known as the extrinsic pathway, involves the tumor necrosis factor (TNF) receptor superfamily of proteins, including Fas and TNFR1, conveying the death signals through DEDs. Phosphorylation of $\mathrm{Ser}^{116}$ regulates the anti-apoptotic function of PEA-15 and modulates its targeting to the death-inducing signaling complex (Xiao et al. 2002).

PEA-15 inhibits cell proliferation (Formstecher et al. 2001) and is more abundantly expressed in terminally differentiated cells promoting survival (Renault-Mihara et al. 2006). The $C$ terminus of PEA- 15 contains residues required for ERK 1/2 binding (Ramos et al. 1998, Formstecher et al. 2001, Hill et al. 2002). Upon various stimuli, ERK1/2 translocates to the nucleus allowing it to phosphorylate several transcription factors, required for entry into the cell cycle (Brunet et al. 1999). The nuclear import and export of ERK $1 / 2$ are regulated by a variety of protein-protein interactions that therefore serve as control points in cell proliferation. Interestingly, PEA-15 is one of the proteins identified to bind to 
ERK1/2 and to regulate its subcellular localization. By various mechanisms, PEA-15 expression leads to a retention of ERK in the cytoplasm (Formstecher et al. 2001, Whitehurst et al. 2004).

The amino acid sequence of PEA-15 is conserved in human, mouse, rat, and hamster, and this protein is expressed in many tissues including brain, breast, lung, and prostate (Araujo et al. 1993, Danziger et al. 1995, Estelles et al. 1996). Thus far, the expression of PEA-15 in the testis has not been studied. In preliminary studies (unpublished results), we found an increased expression of PEA-15 in Sertoli cells exposed to doxorubicin. In this study, we demonstrate the presence of PEA-15 in the testis and we studied some functional aspects of PEA-15 in spermatogenesis, also using PEA-15-deficient mice.

\section{Materials and Methods}

\section{Experimental animals}

Eight-week-old PEA-15 ground and wild type (WT) littermates were generated as described previously (Kitsberg et al. 1999) and maintained at Collège de France, Paris, France.

Adult CD-1 mice were purchased from Charles River (Wilmington, MA, USA) and used and maintained according to the regulations provided by the Animal Ethics Committee of the University of Utrecht, which also approved the experiments.

The mice were killed by $\mathrm{CO}_{2}$ asphyxiation and the testes were fixed in RNase-free Bouin's solution or 4\% paraformaldehyde (PFA) for histology, immunohistochemistry, and in situ hybridization purposes.

\section{Immunohistochemistry}

\section{Anti-PEA-15 antibody staining}

For immunolocalization of PEA-15, $5 \mu \mathrm{m}$ paraffin sections were mounted on 3-aminopropyl triethoxysilane (TESPA, Sigma)-coated glass slides and dried overnight at $37^{\circ} \mathrm{C}$. A 10-min antigen retrieval (sodium citrate buffer, $0.1 \mathrm{mM}, \mathrm{pH}$ 6) step was performed at $700 \mathrm{~W}$ in a microwave oven thrice (Polaron H2500 Microwave Processor, BioRad). Endogenous peroxidase was blocked with $0.35 \% \mathrm{H}_{2} \mathrm{O}_{2}$ in PBS for $15 \mathrm{~min}$. After blocking in 5\% normal horse serum (Vector Laboratories, Burlingame, USA), slides were consecutively incubated with avidin and biotin blocking solutions (Vector Laboratories) and then with 1:1000 Ab-7 rabbit polyclonal anti-PEA-15 antibody (Sharif et al. 2004) in $1 \%$ BSA in PBS for $1 \mathrm{~h}$ at $4{ }^{\circ} \mathrm{C}$ (Sigma). Subsequently, the sections were incubated with PowerVision poly HRPanti-mouse/rabbit/rat IgG (one component) ready-to-use secondary antibody (\#DPVO-110HRP, Immunologic, ImmunoVision Tech. Co., Brisbane, CA, USA) for $30 \mathrm{~min}$ at room temperature. Antibody was finally detected using diaminobenzidine (DAB; Sigma) in
$50 \mathrm{mM}$ Tris- $\mathrm{HCl}$ (pH 7.6). Sections were counterstained with hematoxylin, dehydrated, and mounted with Pertex (Cellpath Ltd, Hemel Hempstead, UK).

Rabbit IgG (sc-2025, Santa Cruz Biotechnology, Santa Cruz, CA, USA) was used to replace the primary antibody in immunohistochemistry to check the specificity of the staining. Experiments were repeated at least thrice.

\section{Anti-ERK2 staining}

Paraffin sections were mounted on coated glass slides and dried overnight at $37{ }^{\circ} \mathrm{C}$. Endogenous peroxidase was blocked with $3 \% \mathrm{H}_{2} \mathrm{O}_{2}$ in PBS for $10 \mathrm{~min}$. After blocking in 5\% normal goat serum (Vector Laboratories) in $1 \%$ BSA in PBS (Sigma) for a minimum of $15 \mathrm{~min}$, the sections were incubated with mouse monoclonal anti-ERK2 primary antibody (sc-1647, Santa Cruz Biotechnology) with 1:100 dilution in 1\% BSA in PBS for $1 \mathrm{~h}$ at room temperature. Subsequently, the sections were incubated with PowerVision poly HRP-anti-mouse IgG, ready-to-use secondary antibody (\#DPVM-110HRP, ImmunoVision Tech. Co.) for $30 \mathrm{~min}$ at room temperature, according to manufacturer's instructions. DAB was used as chromogen for detection. Sections were counterstained with hematoxylin, dehydrated, and mounted with Pertex (Cellpath Ltd).

A blocking peptide specific for ERK2 (sc-1647-p, Santa Cruz Biotechnology) was used to monitor the specificity of the staining. Experiments were repeated at least thrice.

\section{Preparation of RNA probes}

An approximately 116 bp mouse PEA-15 cDNA insert, cloned in the vector pGEM-T-Easy (Promega), was linearized by Pstl and Sphl and in vitro transcribed to generate antisense and sense digoxigenin (DIG)-labeled cRNAs using DIG-RNA labeling mix (Roche), and T7 RNA polymerase and SP6 RNA polymerase respectively, according to manufacturer's instructions.

\section{Cell culture}

SK49 and TM4 Sertoli cell lines were grown at $37{ }^{\circ} \mathrm{C}$ in a humidified incubator under $5 \% \mathrm{CO}_{2}, 95 \%$ air in $\mathrm{MEM}$ supplemented with $2.5 \%$ FBS, in culture flasks. Culture medium was replaced twice a week. At confluency, cells were passaged following trypsinization with $0.25 \%$ trypsin-EDTA solution (Life Technologies).

\section{In situ hybridization}

An in situ hybridization protocol was applied as described earlier (Mizrak et al. 2006). Initially, a postfixation step was performed with $4 \%$ paraformaldehyde for $15 \mathrm{~min}$ at room temperature followed by a digestion step with proteinase $\mathrm{K}$ at a concentration of $10 \mu \mathrm{g} / \mu \mathrm{l}$ and 
again a second post-fixation step. Then, a DNase (Roche; RNase free, $100 \mathrm{IU}$ in PBS) control was introduced for $1 \mathrm{~h}$ at $37{ }^{\circ} \mathrm{C}$. Hybridization was carried out overnight at $55{ }^{\circ} \mathrm{C}$ with $200 \mathrm{ng} / \mathrm{ml}$ PEA-15 digoxigenin-labeled RNA probes in the hybridization solution $10 \%$ dextran sulfate, $4 \times$ SSC $(1 \times$ SSC consists of $150 \mathrm{mM} \mathrm{NaCl}$, $15 \mathrm{mM}$ sodium citrate, $\mathrm{pH} 7.2$ ), 50\% formamide, $10 \mathrm{mM}$ dithiothreitol (DTT), $0.25 \mathrm{mg} / \mathrm{ml}$ poly $\mathrm{A}$, $0.25 \mathrm{mg} / \mathrm{ml}$ denatured and sheared herring sperm DNA, and $1 \times$ Denhardt's buffer), following $2 \mathrm{~h}$ of prehybridization step at $55{ }^{\circ} \mathrm{C}$. After hybridization, sections were quickly washed with $1 \times$ SSC (containing $10 \mathrm{mM}$ DTT) at room temperature, two successive washes of 15 min were done with $1 \times$ SSC (containing $10 \mathrm{mM} \mathrm{DTT}$ ) at $55{ }^{\circ} \mathrm{C}$, with further two washes of 15 min with $0.5 \times$ SSC (containing $10 \mathrm{mM}$ dithiothreitol) also at $55^{\circ} \mathrm{C}$. RNase treatment was introduced immediately after the stringency washes. The slides were then washed thrice with Tris-buffered saline (TBS) and incubated for $30 \mathrm{~min}$ in a blocking solution (TBS $+0.3 \%$ Triton $\mathrm{X}-100+2 \%$ normal sheep serum). The RNA probes were detected using a polyclonal anti-digoxigenin antibody (\#1333089, Roche) in a 1:100 dilution in the blocking solution. After overnight incubation at $4{ }^{\circ} \mathrm{C}$, the slides were washed four times with TBS (10 min each) and incubated with the biotinylated anti-sheep secondary antibody (Vector Laboratories) 1:100 dilution in PBS for $1 \mathrm{~h}$ at room temperature. Horseradish peroxidaseavidin-biotin complex reaction was performed according to manufacturer's protocol (Vector Laboratories). Finally, detection was done using DAB (Sigma) in $50 \mathrm{mM}$ Tris- $\mathrm{HCl}(\mathrm{pH}$ 7.6). Sections were counterstained with hematoxylin, dehydrated, and mounted with Pertex (Cellpath Ltd). The in situ hybridization experiments were repeated at least thrice.

\section{RT-PCR}

RNA was extracted from mouse testis and mouse-derived SK49 (Walther et al. 1996) and TM4 (Mather 1980) Sertoli cell lines using the FastRNA Pro Green kit (Qbiogene, Illkirch Cedex, France), according to manufacturer's instructions. Two micrograms of each total RNA fraction were reverse transcribed in a $20 \mu \mathrm{l}$ volume, using random hexamers and the Superscript II pre-amplification system (Invitrogen), according to manufacturer's instructions. RT reactions were performed with $(+R T)$ and without $(-R T)$ Superscript II reverse transcriptase.

Each type of cDNA was used as a template for PCR amplification using the PEA-15-specific forward primer 1663 (5'-CAGCTCAAGTCAGCCTGCAA-3') and reverse primer 1664 (5'-CTTGTTGTGGCTCTCCAGGAA-3'). PCRs were carried out in $50 \mu \mathrm{l}$ volumes, each containing $50 \mathrm{mM} \mathrm{KCl}, 10 \mathrm{mM}$ Tris- $\mathrm{HCl}(\mathrm{pH} 8.3$ ), $1.5 \mathrm{mM} \mathrm{MgCl}$, $0.01 \%$ gelatin, $200 \mu \mathrm{M}$ of each dNTP, 50 pmol primer 1663, $50 \mathrm{pmol}$ primer $1664,1 \mu \mathrm{l}$ cDNA, and $1 \mathrm{U}$
SuperTaq (HT Biotechnologies Ltd, Cambridge, UK). PEA-15-specific PCR products of $\approx 100 \mathrm{bp}$ were visualized on $2 \%$ agarose gel.

\section{TUNEL on PEA-15 ${ }^{-/-}$and WT testis}

Bouin's fixed, paraffin-embedded testis sections were boiled for $5 \mathrm{~min}$ in $10 \mathrm{mM}$ citric buffer $\left(\mathrm{pH} \mathrm{6.0)}\right.$ at $98{ }^{\circ} \mathrm{C}$ and slowly cooled to room temperature. Endogenous peroxidase was blocked with $3 \% \mathrm{H}_{2} \mathrm{O}_{2}$ in MilliQ for $5 \mathrm{~min}$. Sections were washed thrice with PBS before 60-min incubation in TUNEL mix at $37{ }^{\circ} \mathrm{C}$. TUNEL mix consists of $0.3 \mathrm{U} / \mathrm{ml}$ calf thymus terminal deoxynucleotidyl transferase (Amersham Biosciences), $6.66 \mu \mathrm{M} / \mu \mathrm{l}$ biotin dUTP (Roche) in terminal transferase buffer (Amersham Biosciences). The TUNEL reaction was stopped by incubation in $300 \mathrm{mM} \mathrm{NaCl}, 30 \mathrm{mM}$ sodium citrate in Milli Q water for $15 \mathrm{~min}$ at room temperature. After washing in PBS, sections were blocked with $2 \%$ BSA (Sigma) in PBS at room temperature for $10 \mathrm{~min}$. Sections were treated for $30 \mathrm{~min}$ at $37{ }^{\circ} \mathrm{C}$ in a moist chamber with a 1:20 dilution of ExtrAvidin peroxidase antibody (E2886, Sigma). After three washes in PBS, detection was performed with DAB + (Dako, Glostrup, Denmark). Sections were counterstained with Mayer's hematoxylin, dehydrated, and mounted with Pertex (Cellpath Ltd).

The numbers of TUNEL-positive cells were counted in both testis types and calculated as numbers per 100 tubule cross sections. At least 100 tubules per animal were studied. The numbers were expressed as mean \pm S.E.M. and statistical analysis was performed using the split-plot ANOVA (mixed model analysis). The model assumptions for ANOVA are equal variances in the groups which are compared and a normal distribution of the data. Both assumptions were checked.

For the analysis of possible differences per epithelial stage in PEA-15 KO and WT mice with respect to mean numbers of apoptotic cells, we used split-plot ANOVA. This analysis showed a significant interaction between the mouse type and the stage $(P=0.001)$, and therefore, performed post hoc testing at each stage to determine whether there was a difference between the two mouse types. This was done by performing an ANOVA at each stage (in essence this is a two-sample independent $t$-test). Consequently, a Bonferroni correction was performed.

\section{SDS-PAGE and western blotting}

Protein lysates from PEA-15 KO and WT testes were prepared in radio-immunoprecipitation assay (RIPA) buffer (PBS, 1\% NP40, 0.5\% sodium deoxycholate, $0.1 \%$ SDS) including $1 \mathrm{mM}$ phenylmethylsulfonyl fluoride. Of each sample, $50 \mu \mathrm{g}$ were separated on a $12 \%$ SDS-polyacrylamide gel and blotted onto a polyvinylidene fluoride membrane (Millipore Corp., Bedford, MA, USA). Western blots were blocked using 
Blotto-A, containing 5\% Protifar (Nutricia, Zoetermeer, The Netherlands) in TBS (10 mm Tris; $150 \mathrm{~mm} \mathrm{NaCl}, \mathrm{pH}$ 7.6), including $0.05 \%$ Tween 20 . Rabbit monoclonal anti-phospho-p44/42 MAPK (4376, Cell Signaling) antibody was diluted 1:500 in Blotto-A and incubated overnight at $4{ }^{\circ} \mathrm{C}$. The blot was washed with TBS including $0.05 \%$ Tween 20 . After incubation with a 1:1000 dilution of anti-rabbit-HRP secondary antibody (P-0260, DAKO Cytomation) for $1 \mathrm{~h}$, blots were incubated with ECL and exposed to X-ray film (RXomat, Kodak). For internal control, anti- $\alpha$-tubuline antibody (MS-581-PO, Neomarkers, Freemont, CA, USA) was applied to the blot.

\section{Results}

\section{Localization of PEA-15}

Immunohistochemistry, applying the A-7 polyclonal antibody against PEA-15 (Sharif et al. 2004), resulted in the localization of the PEA-15 protein in the cytoplasm of Sertoli cells and all A spermatogonia, intermediate (In) spermatogonia, and B spermatogonia (Fig. 1A). Furthermore, there was a remarkable staining in the cytoplasm of preleptotene and leptotene spermatocytes (Fig. 1C and D). The staining that became weaker with the ongoing development was observed in the cytoplasm of pachytene spermatocytes, and staining was faint in the cytoplasm of diplotene spermatocytes (Fig. 1C). No staining was detected in spermatids (Fig. 1D). A PEA-15 ${ }^{-1-}$ mouse testis was used as a negative control for the immunohistochemistry together with rabbit IgG in a concentration equal to the $\lg G$ concentration of the applied antibody. We did not detect any staining in testis sections of PEA-15 null mice (Fig. 1B) and in the IgG controls (not shown).

The in situ hybridization analysis showed the PEA-15 mRNA to be present in germ cells and Sertoli cells in all stages of the cycle of the seminiferous epithelium (Fig. 2A). After hybridization, RNase treatment was carried out to see whether the signal was specific (Fig. 2C). As another control, the DIG-labeled sense riboprobe was applied in the same concentration as the antisense probe, and no signal was detected (Fig. 2B). PEA-15 mRNA was localized in the cytoplasm of all spermatogonial cell types, and preleptotene and leptotene spermatocytes (Fig. 2C and D). The PEA-15 mRNA was also detected in the cytoplasm of Sertoli cells (Fig. 2C and D). The signal started to diminish in pachytene spermatocytes and completely disappeared in diplotene spermatocytes. Round and elongated spermatids did not express PEA-15 mRNA (Fig. 2C and D).

The presence of PEA-15 in the mouse testis and mouse-derived SK49 and TM4 Sertoli cell lines was studied using the RT-PCR technique. Expression of PEA15 was found in SK49 and TM4 Sertoli cell lines and in the mouse testis (data not shown).

\section{Apoptosis of germ cells in WT and PEA-15 knockout mice}

Complete spermatogenesis was observed in the PEA-15 $\mathrm{KO}$ mouse testis. However, the number of apoptotic germ cells seemed higher than that in controls. Therefore, we performed TUNEL labeling to detect apoptotic germ cells (Fig. 3A and B). Especially in the PEA-15-deficient testis, we observed apoptotic spermatogonia, spermatocytes, and round spermatids, whereas spermatocytes were the
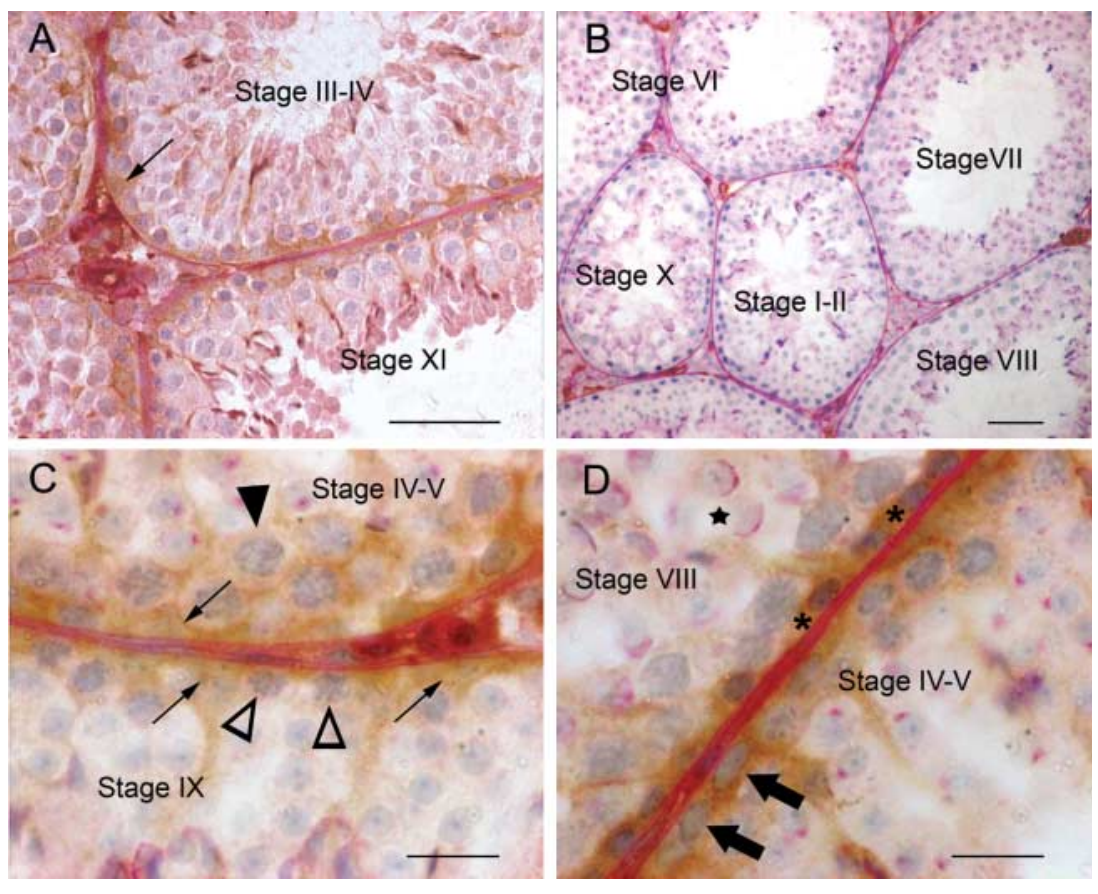

Figure 1 Detection of PEA-15 protein in mouse seminiferous tubules. A: Cells in all tubules stain positive for PEA-15, B: No staining is observed in the PEA-15 null mouse testis, C and D: Sertoli cells show a cytoplasmic staining (thin arrow). Staining for PEA-15 is also observed in pachytene spermatocytes (arrow head), preleptotene spermatocytes (asterisk), leptotene spermatocytes (hollow arrow head), and B spermatogonia (thick arrow). No staining is present in round spermatids (star). Bars represent: A and B, $30 \mu \mathrm{m} ; \mathrm{C}$ and D, $10 \mu \mathrm{m}$. 

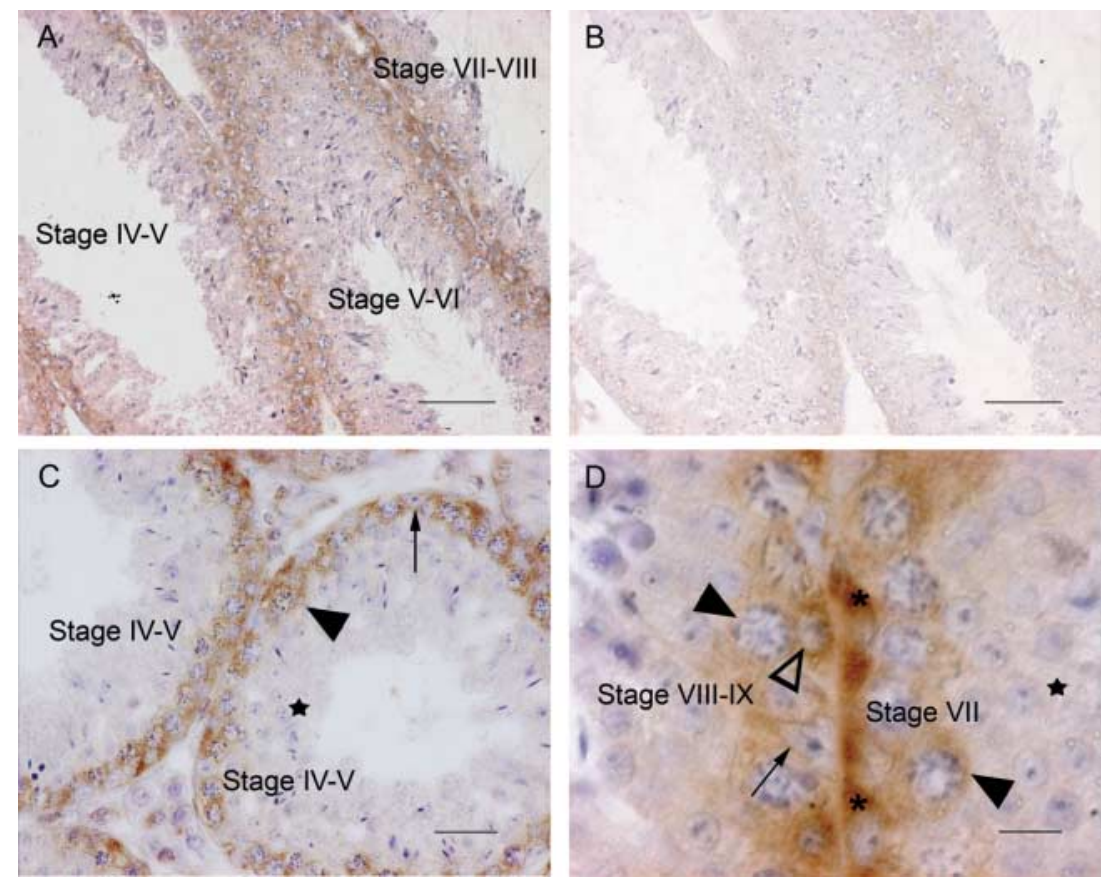

Figure 2 In situ hybridization for PEA-15 mRNA. A: Antisense probe hybridized slide, staining is present in all tubules. B: Sense riboprobe hybridized slide as a negative control, no staining is observed. C: RNase-treated control slide. mRNA localization can be seen in the cytoplasm of Sertoli cell (thin arrow) and in that of pachytene spermatocytes (arrow head). No mRNA localization in round spermatids is observed (star), D: Antisense probe hybridized slide, staining is seen in all tubules. mRNA localization is present in the cytoplasm of Sertoli cell (thin arrow), pachytene spermatocytes (arrow head), leptotene spermatocytes (hollow arrow head), and preleptotene spermatocytes (asterisk). No mRNA localization in round spermatids (star). Bars represent: A and B, $100 \mu \mathrm{m} ; \mathrm{C}, 50 \mu \mathrm{m} ; \mathrm{D}, 10 \mu \mathrm{m}$. most affected cell type. Therefore, we determined the numbers of TUNEL-positive spermatocytes per 100 seminiferous tubule cross sections. At least 100 tubules per animal were studied. We found a clear, statistically significant increase in the numbers of apoptotic spermatocytes in PEA-15 $5^{-/-}$versus WT testes (Fig. 4).

We also studied the distribution of the apoptotic spermatocytes over the epithelial cycle to see whether the increased apoptosis could be traced to a specific step in the development of the spermatocytes. For that purpose, we counted on an average 234 tubules per testis. The increase in the numbers of apoptotic spermatocytes was found to be not stage specific (Fig. 5). Differences in the numbers of apoptotic spermatocytes in stages IX and XI reached significance in PEA-15 $5^{-1-}$ testes compared with WT testes (Fig. 5).

\section{Localization of ERK2}

We performed immunohistochemistry to localize the ERK2 protein in both WT and PEA-15 knockout mouse testes. In the WT testis, ERK2 was localized in the cytoplasm of Sertoli cells, B spermatogonia, preleptotene, leptotene, and zygotene spermatocytes. Especially in spermatocytes, also some nuclear staining for ERK2 was found (Fig. 6A and C). In contrast, in the KO testis, ERK2 was primarily localized in the nuclei of B spermatogonia, preleptotene, leptotene, and zygotene spermatocytes, while only a weak staining was observed in the cytoplasm of these germ cells and Sertoli cells (Fig. 6B and D).

To study the active form of ERK2, western blotting of proteins of PEA-15 KO and WT testes was carried out. No difference was found in phosphorylated ERK2 expression in PEA-15 $5^{-1-}$ versus WT mice testes (Fig. 7A and B). However, phosphorylated ERK1 expression, which was also detected by the antibody, decreased in PEA-15 mice testes compared with WT testes (Fig. 7C).

\section{Discussion}

The present results show that PEA-15 is expressed in the testis, both in Sertoli cells and in germ cells up till shortly
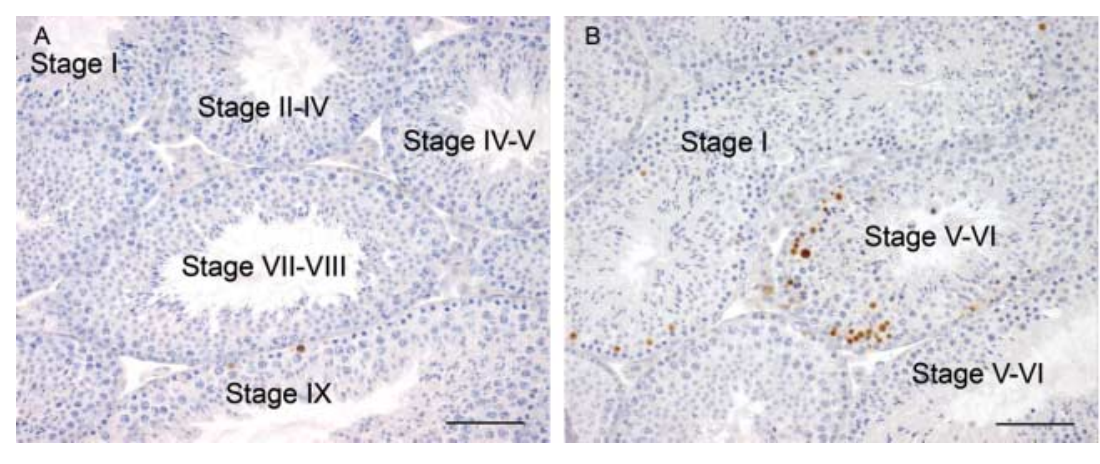

Figure 3 TUNEL analysis of apoptotic cells (brown) in A seminiferous tubules of wild type mice, B the PEA-15 KO mouse testis showing increased numbers of apoptotic germ cells. Bars represent $50 \mu \mathrm{m}$. 


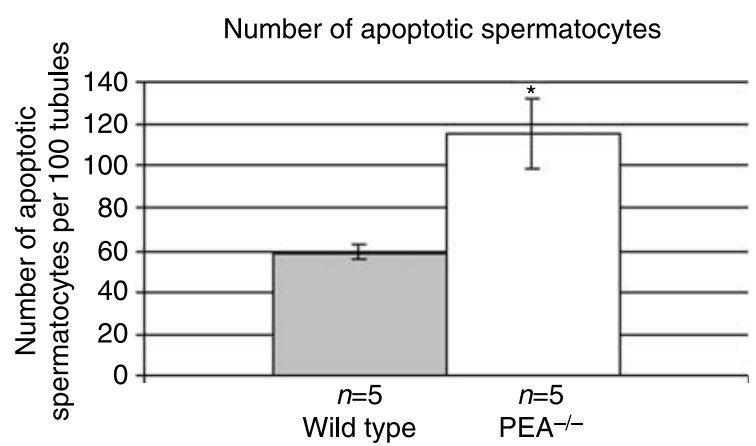

Figure 4 Numbers of apoptotic spermatocytes in wild type and PEA-15 $\mathrm{KO}$ testes.

Distribution of apoptotic germ cells in epithelial stages PEA-15 KO vs WT mice testes

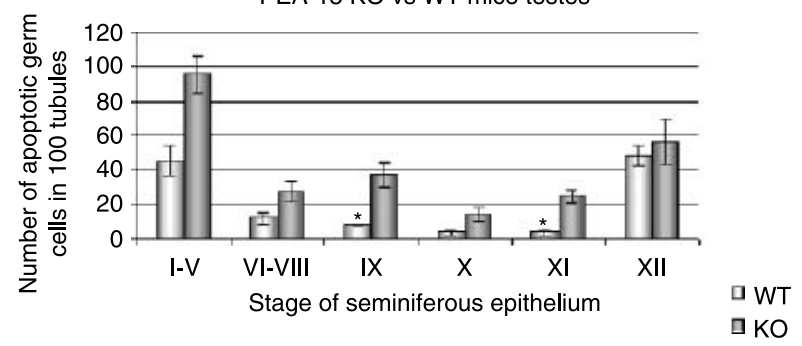

Figure 5 Distribution of apoptotic cells in various epithelial stages of the seminiferous epithelium of wild type and PEA-15 KO mice.

before the end of the meiotic prophase and the meiotic divisions. In the testis too, it appeared to have an antiapoptotic role as enhanced germ cell death occurred in the PEA-15-deficient testis.

The PEA-15 protein and mRNA were found in the cytoplasm of Sertoli cells and all A, In, and B spermatogonia, preleptotene, and zygotene spermatocytes. Subsequently, in the cytoplasm of pachytene spermatocytes, the expression decreased with ongoing development of these cells and expression was very weak in diplotene spermatocytes. In these cell types, the PEA-15 protein and mRNA were found to be present simultaneously.

To learn more about the function of PEA-15 in the testis, we studied testes of PEA-15-deficient mice. Spermatogenesis was found to be apparently normal, except for a virtual doubling in the number of apoptotic spermatocytes in PEA-15-deficient mice compared with WT mice. Counts of apoptotic spermatocytes revealed that the increase in apoptosis was not restricted to a specific step in spermatocyte development but occurred throughout the epithelial cycle. Apparently, PEA-15 has an anti-apoptotic function throughout the meiotic prophase. This is in contrast to the situation in mice deficient in various other proteins with a function during meiosis, such as Msh5, Atm, Dmc1, and Spo11, in which massive apoptosis of spermatocytes occurs specifically in epithelial stage IV (de Vries et al. 1999, de Rooij \& de Boer 2003, Hamer et al. 2004, Barchi et al. 2005).

Spermatocytes have been found to express the FAS receptor and Sertoli cells are known to express and secrete FAS ligand (FasL; Lee et al. 1999). Soon after and dependent on the ligation of FasL to its receptor, FasL induces caspase-8 or -10 activation (Ohta et al. 1996, Blanco-Rodriguez \& Martinez-Garcia 1998, Lee et al. 1999, Lue et al. 1999), and in this process, PEA-15 functions by blocking caspase- 8 activation (Tschopp et al. 1998). In view of this, it is possible that the increased germ cell apoptosis in the PEA-15 KO mouse
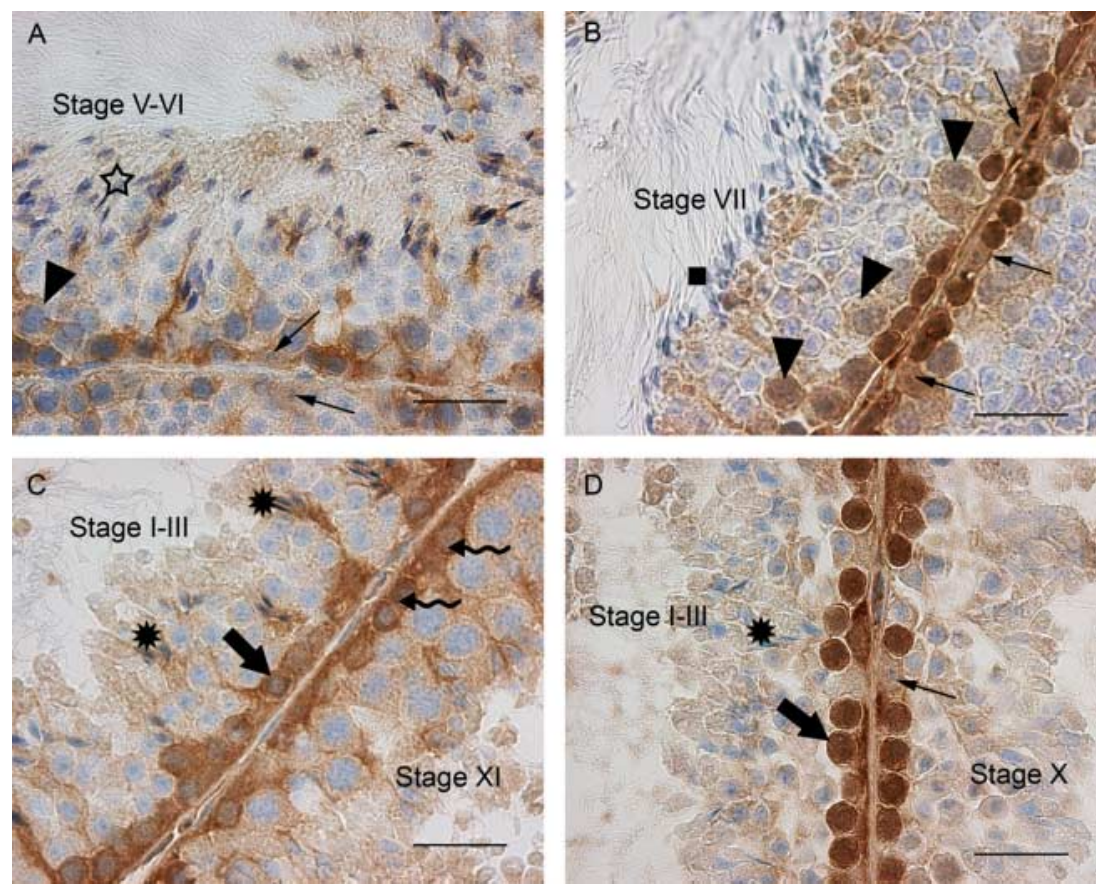

Figure 6 Detection of ERK2 protein in WT and PEA-15 KO mouse seminiferous tubules. A WT mouse seminiferous tubule in stages $\mathrm{V}-\mathrm{VI}$ and step 15 spermatids are depicted (hollow star). Cytoplasmic staining present in Sertoli cells (thin arrow) and pachytene spermatocytes (arrow head), B PEA-15 KO mouse seminiferous tubule in epithelial stage VII and step 16 spermatids are depicted (square). Cytoplasmic staining present in Sertoli cell (thin arrow), and also a nuclear staining is seen in preleptotene and pachytene spermatocytes (arrow head), C WT mouse seminiferous tubule in epithelial stages I-III and step 13 spermatids (10-point star) and stage $\mathrm{XI}$ are depicted. Cytoplasmic staining is shown in early pachytene spermatocytes (thick arrow) and zygotene spermatocytes (wavy arrow), D KO mouse seminiferous tubule in stages I-III and step 13 spermatids (10-point star) and stage $X$ are depicted. Weak cytoplasmic staining is shown in Sertoli cell (thin arrow) and very dense nuclear staining in early pachytene spermatocytes (thick arrow). Bars represent $25 \mu \mathrm{m}$. 

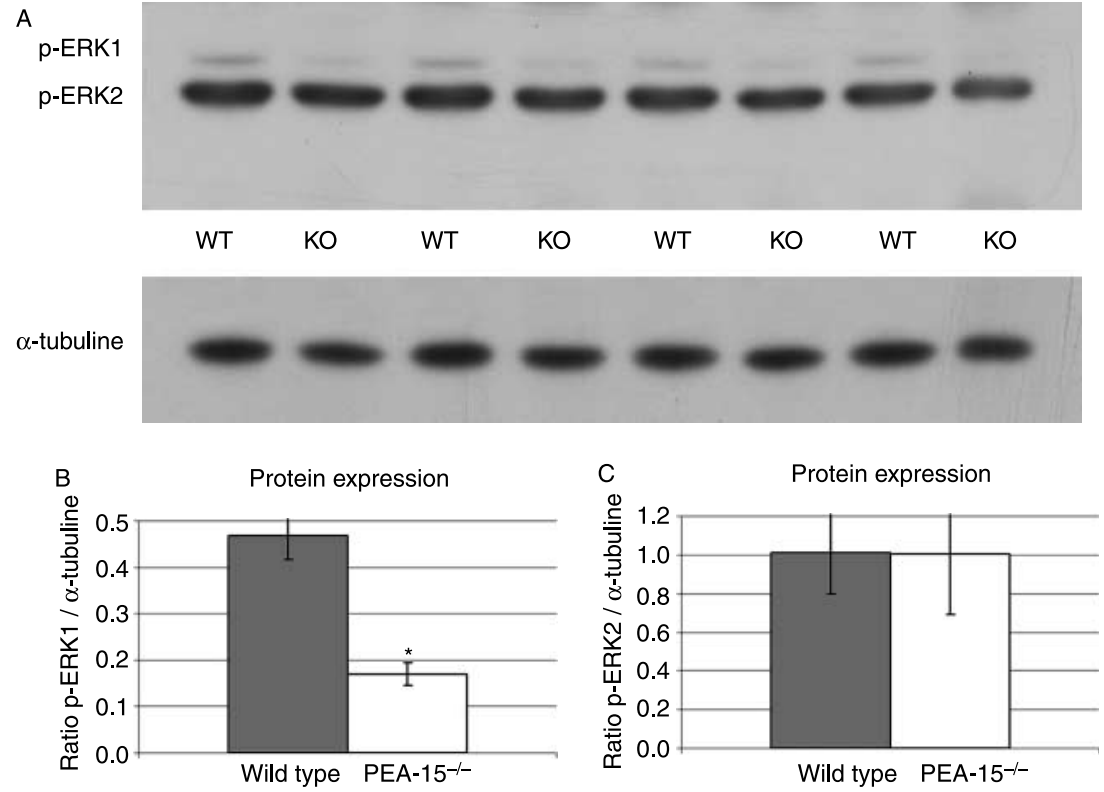

Figure $7 \mathrm{~A}$ : Western blot analysis of phosphorylated ERK1/phosphorylated ERK2 protein expression and internal control, $\boldsymbol{\alpha}$-tubuline expression in WT versus PEA-15 KO mouse testes, B: Quantification of western blot analysis of phosphorylated ERK1/phosphorylated ERK2 protein expression in WT versus PEA-15 KO mouse testes compared with $\alpha$-tubuline expression, C: Quantification of western blot analysis of phosphorylated ERK1 protein expression in WT versus PEA-15 KO mouse testes compared with $\alpha$-tubuline expression. testis is due to the lack of inhibition of caspase- 8 activation in spermatocytes, subsequently causing apoptosis of some of these cells.

Previously, we found an increased expression of PEA15 in Sertoli cells exposed to doxorubicin, which was shown to be a reprotoxicant capable of altering gene expression (Bonilla \& del Mazo 2003). Possibly, the upregulation of PEA-15 is a cellular response to toxicants to protect the cells from apoptosis.

ERK1 and ERK2 are the two major isoforms of ERK and they are activated by phosphorylation (Blenis 1993). ERK2 seems to be the most important isoform as its knockout, but not that of ERK1, is embryonic lethal in mice (Wong \& Cheng 2005). PEA-15 has a function in the MAPK pathway by controlling ERK2 subcellular localization, i.e., maintaining ERK2 in the cytoplasm of cells, and thereby inhibiting its proliferation-stimulating function (Goldberg 1999, Formstecher et al. 2001, Janssens \& Goris 2001, Janssens et al. 2005). Therefore, we studied ERK2 localization in the WT testis, where it was found mainly in the cytoplasm of Sertoli cells, B spermatogonia, and early spermatocytes, although some immunoreactivity was found in the nuclei of these cells. In contrast, in the PEA-15 KO testis, ERK2 was mainly localized in the nuclei of Sertoli cells, B spermatogonia, and early spermatocytes, and only little staining was observed in the cytoplasm of these cells. The massive translocation to the nucleus of the activated ERK2 in the testis of PEA-15-deficient mice in spermatocytes may also have led to increased apoptosis of these cells. The meiotic prophase is a complex and strictly regulated process and the abnormal presence and proliferationstimulating activity of ERK-2 in the spermatocyte nuclei may be fatal to some of these cells. Despite the difference in subcellular localization of ERK2, western blotting did not detect any difference in the amount of phosphory-

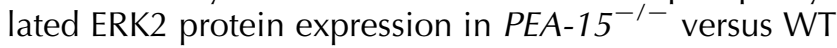
mice testes.

Okadaic acid (OA) causes meiotic progression and chromosome condensation in pachytene spermatocytes (Wiltshire et al. 1995, van den Ham et al. 2003). It has been shown that preincubation of cultured pachytene spermatocytes, with a selective inhibitor of ERKactivating kinases, MEK1/2, completely blocks the ability of $\mathrm{OA}$ to induce chromosome condensation and progression to meiotic metaphase (Sette et al. 1999). This suggests that ERK1 is specifically activated during $\mathrm{G}_{2} / \mathrm{M}$ transition in mouse spermatocytes, that it contributes to the mechanisms of maturation promoting factor activation, and that it is essential for chromosome condensation associated with progression to meiotic metaphases (Sette et al. 1999). Interestingly, in the present study, phosphorylated ERK1 expression was found to be decreased in PEA-15 $5^{-1-}$ mice testes compared with WT testes. This might be another cause for increased apoptosis of spermatocytes in PEA-15 knockout mice.

Inselman \& Handel (2004) investigated the expression of ERK1 and ERK2 during spermatogenesis by western blot analysis of isolated cell types using an ERK antibody which recognizes both 44 kDa ERK1 and 42 kDa ERK2 proteins with similar specificity. ERK2 protein was demonstrated to be present in all types of germ cells in the testis. In the same study, ERK1 and ERK2 were found to be localized throughout the chromatin structure of spermatocytes. In the present study, we have performed immunohistochemistry to investigate the cellular localization pattern of ERK2 protein with an antibody that was used for immunocytochemistry technique by Inselman \& Handel (2004), which only recognizes ERK2. 
We detected the ERK2 protein in Sertoli cells, B spermatogonia, preleptotene, leptotene, and zygotene spermatocytes, but not in spermatids. We have also used p-MAPK antibody for western blotting that was used for immunocytochemistry purpose by Inselman \& Handel (2004). The difference between our study and the previous one (Inselman \& Handel 2004) in finding ERK2 in spermatids may lie in the use of same antibodies in different techniques.

In conclusion, for the first time, we show that PEA-15 is present in the testis in Sertoli cells, all types of spermatogonia, and spermatocytes up till just before meiotic divisions. Spermatogenesis in PEA-15 knockout mice is grossly normal except for a clear increase in spermatocyte apoptosis. The increase in spermatocyte apoptosis in PEA-15 knockout mice may be related to a lesser inhibition of the apoptosis executioner caspases or the observed increased activation of ERK2 in spermatocytes. In that case, the increased apoptosis of spermatocytes is caused by a direct effect of the PEA-15 deficiency on spermatocyte viability. While this possibility seems to be the most likely one, we cannot exclude that PEA-15 deficiency may also compromise Sertoli cell function in such a way that spermatocyte development is insufficiently supported in PEA-15-deficient mice, causing the increased spermatocyte apoptosis. This will have to be studied in further detail. Finally, in contrast to spermatocytes, spermatogonia were apparently not affected by the PEA-15 deficiency. Possibly, PEA-15 in spermatogonia is of less importance or its function can be taken over by other proteins.

\section{Acknowledgements}

This work was supported by E U Grant no. QLK4-CT-200202403. The authors declare that there is no conflict of interest that would prejudice the impartiality of this scientific work.

\section{References}

Araujo H, Danziger N, Cordier J, Glowinski J \& Chneiweiss H 1993 Characterization of PEA-15, a major substrate for protein kinase $C$ in astrocytes. Journal of Biological Chemistry 268 5911-5920.

Barchi M, Mahadevaiah S, Di Giacomo M, Baudat F, de Rooij DG, Burgoyne PS, Jasin M \& Keeney S 2005 Surveillance of different recombination defects in mouse spermatocytes yields distinct responses despite elimination at an identical developmental stage. Molecular and Cellular Biology 25 7203-7215.

Blanco-Rodriguez J \& Martinez-Garcia C 1998 Apoptosis precedes detachment of germ cells from the seminiferous epithelium after hormone suppression by short-term oestradiol treatment of rats. International Journal of Andrology 21 109-115.

Blenis J 1993 Signal transduction via the MAP kinases: proceed at your own RSK. PNAS 90 5889-5892.

Bonilla E \& del Mazo J 2003 Deregulation of gene expression in fetal oocytes exposed to doxorubicin. Biochemical Pharmacology 65 1701-1707.
Brunet A, Roux D, Lenormand P, Dowd S, Keyse S \& Pouyssegur J 1999 Nuclear translocation of p42/p44 mitogen-activated protein kinase is required for growth factor-induced gene expression and cell cycle entry. EMBO Journal 18 664-674.

Condorelli G, Vigliotta G, lavarone C, Caruso M, Tocchetti CG, Andreozzi F, Cafieri A, Tecce MF, Formisano P, Beguinot $L$ et al. 1998 PED/PEA-15 gene controls glucose transport and is overexpressed in type 2 diabetes mellitus. EMBO Journal 17 3858-3866.

Danziger N, Yokoyama M, Jay T, Cordier J, Glowinski J \& Chneiweiss H 1995 Cellular expression, developmental regulation, and phylogenic conservation of PEA-15, the astrocytic major phosphoprotein and protein kinase C substrate. Journal of Neurochemistry 64 1016-1025.

de Rooij DG \& de Boer P 2003 Specific arrests of spermatogenesis in genetically modified and mutant mice. Cytogenetic and Genome Research 103 267-276.

de Vries SS, Baart EB, Dekker M, Siezen A, de Rooij DG, de Boer P \& te Riele H 1999 Mouse MutS-like protein Msh5 is required for proper chromosome synapsis in male and female meiosis. Genes and Development 13 523-531.

Estelles A, Yokoyama M, Nothias F, Vincent JD, Glowinski J, Vernier P \& Chneiweiss H 1996 The major astrocytic phosphoprotein PEA-15 is encoded by two mRNAs conserved on their full length in mouse and human. Journal of Biological Chemistry 271 14800-14806.

Formstecher E, Ramos JW, Fauquet M, Calderwood DA, Hsieh JC, Canton B, Nguyen XT, Barnier JV, Camonis J, Ginsberg MH et al. 2001 PEA-15 mediates cytoplasmic sequestration of ERK MAP kinase. Developmental Cell 1 239-250.

Goldberg Y 1999 Protein phosphatase 2A: who shall regulate the regulator? Biochemical Pharmacology 57 321-328.

van den Ham R, van Dissel-Emiliani FM \& van Pelt AM 2003 Expression of the scaffolding subunit $\mathrm{A}$ of protein phosphatase $2 \mathrm{~A}$ during rat testicular development. Biology of Reproduction $\mathbf{6 8}$ 1369-1375.

Hamer G, Kal HB, Westphal CH, Ashley T \& de Rooij DG 2004 Ataxia telangiectasia mutated expression and activation in the testis. Biology of Reproduction 70 1206-1212.

Hao C, Beguinot F, Condorelli G, Trencia A, Van Meir EG, Yong VW, Parney IF, Roa WH \& Petruk KC 2001 Induction and intracellular regulation of tumor necrosis factor-related apoptosis-inducing ligand (TRAIL) mediated apotosis in human malignant glioma cells. Cancer Research 61 1162-1170.

Hill JM, Vaidyanathan H, Ramos JW, Ginsberg MH \& Werner MH 2002 Recognition of ERK MAP kinase by PEA-15 reveals a common docking site within the death domain and death effector domain. EMBO Journal 21 6494-6504.

Inselman A \& Handel MA 2004 Mitogen-activated protein kinase dynamics during the meiotic G2/MI transition of mouse spermatocytes. Biology of Reproduction 71 570-578.

Janssens V \& Goris J 2001 Protein phosphatase 2A: a highly regulated family of serine/threonine phosphatases implicated in cell growth and signalling. Biochemical Journal 353 417-439.

Janssens V, Goris J \& Van Hoof C 2005 PP2A: the expected tumor suppressor. Current Opinion in Genetics and Development 15 34-41.

Kitsberg D, Formstecher E, Fauquet M, Kubes M, Cordier J, Canton B, Pan G, Rolli M, Glowinski J \& Chneiweiss H 1999 Knock-out of the neural death effector domain protein PEA-15 demonstrates that its expression protects astrocytes from TNFalpha-induced apoptosis. Journal of Neuroscience 19 8244-8251.

Lee J, Richburg JH, Shipp EB, Meistrich ML \& Boekelheide K 1999 The Fas system, a regulator of testicular germ cell apoptosis, is differentially up-regulated in Sertoli cell versus germ cell injury of the testis. Endocrinology 140 852-858.

Lue YH, Hikim AP, Swerdloff RS, Im P, Taing KS, Bui T, Leung A \& Wang C 1999 Single exposure to heat induces stage-specific germ cell apoptosis in rats: role of intratesticular testosterone on stage specificity. Endocrinology 140 1709-1717. 
Mather JP 1980 Establishment and characterization of two distinct mouse testicular epithelial cell lines. Biology of Reproduction 23 243-252.

Mizrak SC, Bogerd J, Lopez-Casas PP, Parraga M, Del Mazo J \& de Rooij DG 2006 Expression of stress inducible protein 1 (Stip1) in the mouse testis. Molecular Reproduction and Development 73 1361-1366.

Ohta Y, Nishikawa A, Fukazawa Y, Urushitani H, Matsuzawa A, Nishina Y \& Iguchi T 1996 Apoptosis in adult mouse testis induced by experimental cryptorchidism. Acta Anatomica 157 195-204.

Ramos JW, Kojima TK, Hughes PE, Fenczik CA \& Ginsberg MH 1998 The death effector domain of PEA-15 is involved in its regulation of integrin activation. Journal of Biological Chemistry 273 33897-33900.

Renault F, Formstecher E, Callebaut I, Junier MP \& Chneiweiss H 2003 The multifunctional protein PEA-15 is involved in the control of apoptosis and cell cycle in astrocytes. Biochemical Pharmacology 66 1581-1588.

Renault-Mihara F, Beuvon F, Iturrioz X, Canton B, De Bouard S, Leonard N, Mouhamad S, Sharif A, Ramos JW, Junier MP et al. 2006 PEA-15 expression inhibits astrocyte migration by a PKC deltadependent mechanism. Molecular Biology of the Cell 17 5141-5152.

Sette C, Barchi M, Bianchini A, Conti M, Rossi P \& Geremia R 1999 Activation of the mitogen-activated protein kinase ERK1 during meiotic progression of mouse pachytene spermatocytes. Journal of Biological Chemistry 274 33571-33579.

Sharif A, Renault F, Beuvon F, Castellanos R, Canton B, Barbeito L, Junier MP \& Chneiweiss H 2004 The expression of PEA-15 (phosphoprotein enriched in astrocytes of $15 \mathrm{kDa}$ ) defines subpopulations of astrocytes and neurons throughout the adult mouse brain. Neuroscience 126 263-275.
Tschopp J, Irmler M \& Thome M 1998 Inhibition of fas death signals by FLIPs. Current Opinion in Immunology 10 552-558.

Walther N, Jansen M, Ergun S, Kascheike B \& Ivell R 1996 Sertoli cell lines established from $\mathrm{H}-2 \mathrm{~Kb}$-tsA58 transgenic mice differentially regulate the expression of cell-specific genes. Experimental Cell Research 225 411-421.

Whitehurst AW, Robinson FL, Moore MS \& Cobb MH 2004 The death effector domain protein PEA-15 prevents nuclear entry of ERK2 by inhibiting required interactions. Journal of Biological Chemistry $\mathbf{2 7 9}$ 12840-12847.

Wiltshire T, Park C, Caldwell KA \& Handel MA 1995 Induced premature G2/M-phase transition in pachytene spermatocytes includes events unique to meiosis. Developmental Biology 169 $557-567$.

Wong CH \& Cheng CY 2005 Mitogen-activated protein kinases, adherens junction dynamics, and spermatogenesis: a review of recent data. Developmental Biology 286 1-15.

Xiao C, Yang BF, Asadi N, Beguinot F \& Hao C 2002 Tumor necrosis factor-related apoptosis-inducing ligand-induced deathinducing signaling complex and its modulation by c-FLIP and PED/PEA-15 in glioma cells. Journal of Biological Chemistry 277 25020-25025.

Received 18 October 2006

First decision 9 November 2006

Revised manuscript received 19 December 2006

Accepted 15 January 2007 